\title{
TECHNOLOGICAL INTEGRATION AND SUSTAINABLE PERFORMANCE IN MANUFACTURING FIRMS
}

\author{
Mohamad Ghozali Hassan $^{1 *}$, Muslim Diekola Akanmu ${ }^{1}$, Rushami Zien Yusoff ${ }^{1}$ \\ ${ }^{1}$ School of Technology Management and Logistics, Universiti Utara Malaysia, \\ 06010 Sintok, Kedah, Malaysia
}

(Received: July 2018 / Revised: September 2018 / Accepted: December 2018)

\begin{abstract}
An excellent way of maintaining business performance is through sustainability; one of the essential elements of the sustainability transition process is the development of an innovative and constructive corporate culture through integration. This study therefore aims to determine the relationship between the integration of technology and sustainable performance. It focuses on Malaysian Standard (MS) ISO (International Organization for Standardization) 14001 certified manufacturing firms in Malaysia. Self-administered surveys were used to gather data and information for the study from 722 organizations operating in Malaysia. The Statistical Package for Social Science (SPSS) was used to analyze the data. The results identify significant associations between technology integration and sustainable performance from the perspective of economic, environmental and social performance. Technological integration has always been a significant predictor of sustainable performance, as it is a necessary and key driver in most industries in the environmental achievements of manufacturing firms. The findings from the study provide specific details on the relationship between the variables employed. Technological integration has been found to have a positive relationship with three dimensions of sustainable performance (the economic, environmental and social). A basis for future research and practical application is provided by a framework of identified associations to improve sustainability performance.
\end{abstract}

Keywords: Economic performance; Environmental performance; Social performance; Sustainability performance; Technology integration

\section{INTRODUCTION}

Sustainable business performance can be achieved when a firm or organization develops continuous value for its stakeholders and shareholders, while keeping abreast with environmental requirements (Brent \& Labuschagne, 2004). An outstanding way of maintaining business performance is through sustainability, and one of the essential features of the sustainability transition process is the development of an innovative and constructive corporate culture through integration (Chen et al., 2010). Such a healthy culture would be able to create a better organizational performance and make optimum use of existing assets in order to create beneficial economic, environmental and societal outcomes (Dunphy, 2011). The results from economic, environmental and social sustainability would ensure satisfaction among shareholders, suppliers, customers, employees and society. According to the International Energy Annual Report (2007), manufacturing industries are globally responsible for the huge

\footnotetext{
*Corresponding author's email: ghozali@uum.edu.my, Tel. +60-19-4732666, Fax. +60-49-287070 Permalink/DOI: https://doi.org/10.14716/ijtech.v9i8.2747
} 
and significant amount of waste generation and resources. Across the world, the manufacturing section is responsible for the generation of 36 percent of carbon dioxide emitted into the atmosphere (OECD, 2009).

According to Kusrini et al. (2015), the development and application of green engineering principles in the academic, industrial and government sectors should be explored in order to promote sustainability and to add value to products. Therefore, the different paradigm focusing on the effects of manufacturing firms' stakeholders, such as customers, employees, shareholders and regulators, requires manufacturing organizations to be more responsive to the environment with respect to their processes and products (Amrina \& Yusof, 2011). Innovations in technological integration and the development of new material products, such as waste-toenergy (alternative energy), composting, anaerobic digestion, pyrolysis and gasification, material recycling, and design modeling that lead to sustainable practices, are essential in achieving a safe and clean environment (Kusrini et al., 2015).

Green Supply Chain Management (GSCM) has been a point of significant interest for practitioners and researchers of supply chain management and operation, due to the awareness of environmental protection on a global level (Abdullah et al., 2014). GSCM concerns the delivery of products and services from suppliers and manufacturers to end customers through material flow, information flow and cash flow, in the context of the environment. To improve sustainable performance among manufacturing firms, GSCM is now considered as an important management tool. GSCM also refers to all the stages of Supply Chain Management (SCM) that must comply with the requirements of environmental protection (Zhu \& Sarkis, 2007). Requirements with regard to the involvement of green supply chain partners have led to the introduction of Green Supply Chain Integration (GSCI), an approach to GSCM. GSCI can be considered as a novel concept when firms develop an approach to strategically integrate with suppliers, customers, logistic, and technology to reduce environmental impacts (Wong et al., 2015). Manufacturers are required to employ GSCI to integrate environmental management practices within their companies, and with suppliers and customers (Shi \& Lin, 2003). This action will enhance inter-firm cooperation and encourage mutual GSCM, as well as influencing firms' sustainable performance (Wu, 2013). Thus, the creation of new technologies that foster research and stimulate innovation is required to accelerate sustainable development in all fields of study related to manufacturing (Berawi, 2017a).

\section{LITERATURE REVIEW}

\subsection{Manufacturing Firms and Environmental Issues}

Liu et al. (2012) define manufacturing firms as "business firms that uses components, parts or raw materials to make a finished good, where these finished goods can be sold directly to consumers or to other manufacturing businesses that use them for making a different product". According to IEA (2007), throughout the world manufacturing firms are significantly responsible for waste generation and the consumption of a huge amount of resources. From 1972 to 2004, there was an increase of 61 percent in energy consumption by manufacturing industries, which comprise one third of the global use of energy. Apart from being the main cause of environmental issues such as overflowing waste sites, diminishing raw material resources and increasing levels of pollution, the manufacturing sector is also responsible for 36 percent of global $\mathrm{CO}_{2}$ emissions (OECD, 2009). Therefore, the focus on the effect of stakeholders in manufacturing industries, such as customers, employees, and regulators, has shifted to seeking more responsibilities from manufacturing organizations towards the environment, with respect to their systems and products (Amrina \& Yusof, 2011). The concept of sustainable manufacturing practices relates to the procedures, policies and techniques used 
by firms in monitoring and controlling the effects of their production processes and operations on the natural environment (Montabon et al., 2007).

\subsection{Sustainable Performance}

Sustainable business performance can be achieved when a firm or company creates continuous value for its stakeholders and shareholders, while keeping abreast with environmental requirements (Brent \& Labuschagne, 2004). There are certain essential aspects of firms' sustainable value, which include showing care for the environment and society, and more importantly, keeping customers and shareholders happy. According to Dunphy (2011), "sustainability consists of actions that extend socially useful life of an organization, enhance the ability to maintain, renew the viability of the biosphere, protect all living species, and enhance the society to maintain itself and to solve its major problem and to maintain welfare, participation and personal freedom for present and future generations of humanity". An effective way of conducting business is through the consideration of sustainability and the transition towards sustainable enterprises, which can be made by developing an innovative and constructive corporate culture. This healthy culture will be able to develop high performance and make maximum use of existing assets in a way that produces good results for the economy, and society (Dunphy, 2011).

\subsubsection{Sustainable economic performance}

Economic sustainability continues to be one of the major goals for businesses. According to Green $\mathrm{Jr}$ et al. (2012), sustainable economic performance is the "evaluation of organizational cost reduction, promotion of market shares, return on assets, and improvement on income and profits regarding the economic goals of performance". The implementation of GSCM practices among manufacturing firms has resulted in better economic performance (Green Jr et al., 2012). The positive results from the economic aspect can be achieved through multiple direct pathways of sustainable supply chain management (Liu et al., 2012). Previous research which has investigated GSCI among Malaysian certified companies has confirmed the positive relationship between economic performance and green supply chain initiatives (Eltayeb et al., 2011). Consumers are the main drivers of green practice implementation and play a significant role by demonstrating their influence and environmental consciousness when choosing companies, thus increasing competitiveness and economic performance (Andiç et al., 2012; Setiawan \& Asvial, 2016).

\subsubsection{Sustainable environmental performance}

Environmental concerns and conscience are driving businesses to consider their operational impacts. According to Junquera et al. (2012), sustainable environmental performance is defined as "the evaluation of reduction in $\mathrm{CO}_{2}$ emissions, efficient energy or resources used and decrease in consumption of hazardous or harmful materials". Sustainable environmental performance is achievement in reducing the resource usage, pollution emitted, and waste generated resulting from the undertaken efforts (Brent \& Labuschagne, 2004). Environmental performance can also be a useful indicator in reducing environmental risks, as well as supporting external communication and policy-making for both public and private sectors (Chien \& Shih, 2007; Mazzi et al., 2012).

\subsection{3.vSustainable social performance}

Firms have a great social responsibility and need to take care of their employees and society. Teraji (2009) defined sustainable social performance as the "evaluation of organization on healthy work environment, social commitment and participation, education and training, and human resources development". The study added that management is increasingly recognizing its responsibility for implementing ethical programs to enhance social welfare, as awareness among consumers of corporate social performance increases. Several areas, namely human resources, corporate governance, human rights, and the environment, should be properly 
assessed (Bessire \& Onnée, 2010). Brent and Labuschagne (2004) refer to sustainable social performance as 'achievements in creating social welfare (for various stakeholders including suppliers, employees, customers and society) resulting from undertaking operational efforts'. In detail, management has full responsibility for the implementation of social commitment and participation, social administrative policies, human resource management, and a healthy working environment.

\subsection{Technological Integration}

Technological integration can be defined as "environmental practices of the use of technology tools taking place between a buying and supplying organization regarding activities such as product development, process reengineering, and technical training" ( $\mathrm{Wu}, 2013$ ). The term 'technology' is broadly defined to include both structural aspects, such as process- and productrelated changes, and managerial techniques and expertise (Vachon, 2003). Technological integration in green supply chain activities is becoming a necessity in most industries due to the rapid movement in green technology (Nidumolu et al., 2009). Innovation in the field is the key driver in achieving sustainable development and aims to reduce the negative impact of product lifecycles on the environment (Dangelico \& Pujari, 2010). Although technological integration is an important part of GSCI, it is always hard to obtain the latest green manufacturing technologies (Wu, 2013). Furthermore, apart from being costly, integration of technology is also challenging and needs to be carried with exhaustive pre-analysis (Nidumolu et al., 2009). Due to this situation, manufacturers are likely to lack the knowledge of green technology. Therefore, they should make an effort to acquire information from the supply chain both internally and externally, through assistance and training, because of their inadequate professional knowledge about processes or new products (Koufteros et al., 2005).

Technological integration plays a significant role in achieving sustainable goals targets by improving the efficiency and effectiveness of new and more sustainable ways of development. The creation of new technologies that foster research and stimulate innovation is thus required. These processes can be boosted by strengthened knowledge sharing and collaboration between manufacturing firms in both national and international contexts (Berawi, 2017b).

\subsection{Relationship between Technological Integration and Sustainable Performance}

A previous study by Huber et al. (2007) shows that the use of technology in the supply chain contributes to effective communication, unique product identification, and real time information. A plethora of technologies with customer-centric and information-intensive features provide enormous benefits, such as reduced costs, increased flexibility, and enhanced coordination (Andiç et al., 2012). Technological integration in green supply chain management should be able to help track the progress of green initiatives practiced in an organization, which automatically increases the possibility of achieving environmental goals (Bushar et al., 2014). However, technological integration still requires the involvement of suppliers and customers in term of product design, training and assistance in improving a company's economic, environmental and social performance (Vachon, 2003). The relationship between technological integration and performance is interconnected, as shown by several empirical studies (Huber et al., 2007; Gunasekaran et al., 2008; Andiç et al., 2012; Bushar et al., 2014;). However, to date there has been no investigation linking technological integration from the GSCM aspect and organizational sustainable performance, in relation to the three dimensions of the economy, environment and society. There remain limitations to GSCI conceptualization if technological integration is ignored ( $\mathrm{Wu}, 2013)$. This requires further investigation of the association between technological integration and sustainable performance.

Therefore, this study focuses on the relationship between technological integration, as an element of green supply chain integration (GSCI), and the sustainable performance (SP) of ISO 
14001 certified manufacturing firms in Malaysia. The theoretical framework of the study is shown in Figure 1.

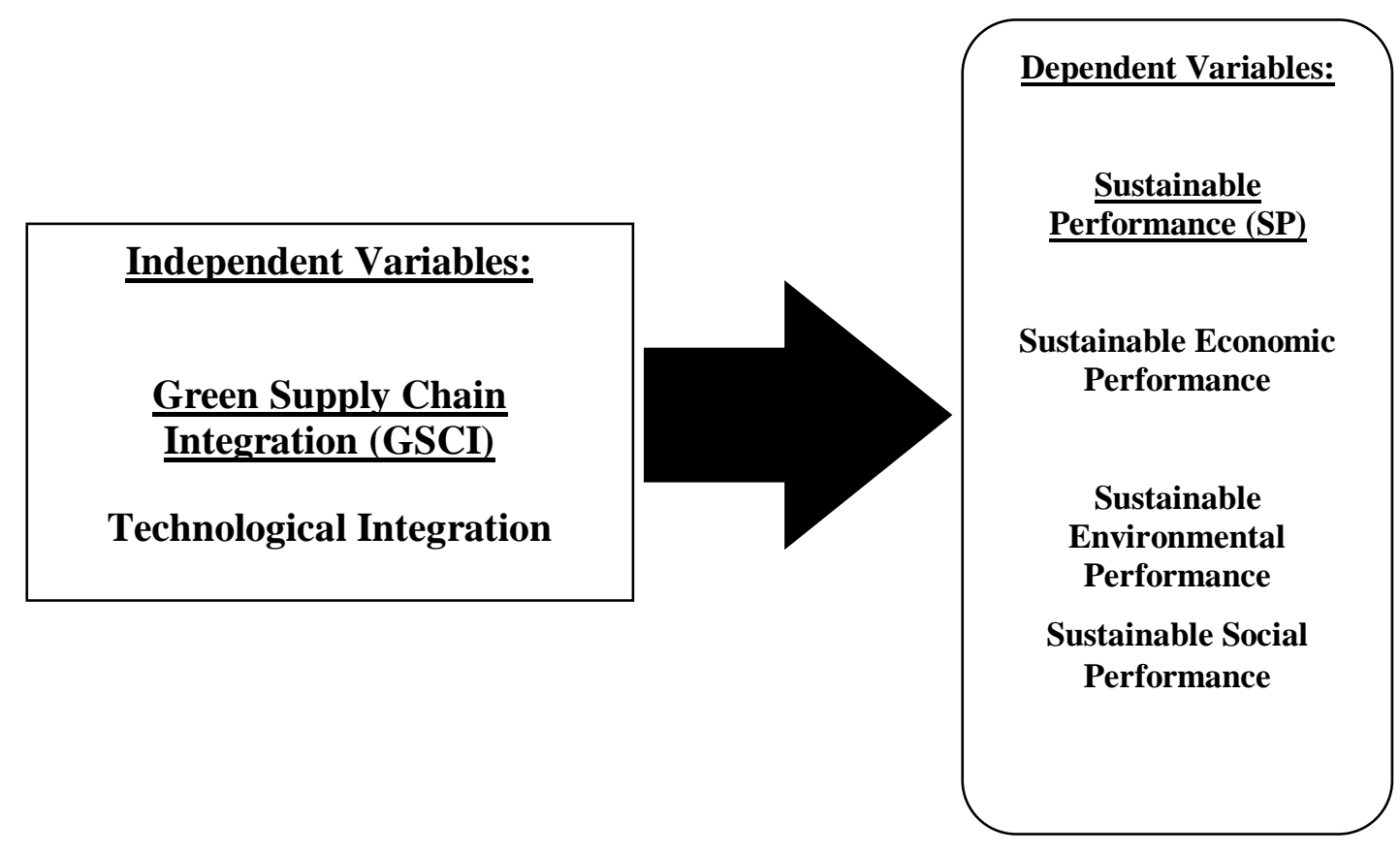

Figure 1 Theoretical framework linking the dependent and independent variables

The experiment was carried out in a parallel plate DBD plasma reactor. The parallel plate plasma reactor was designed by modifying the ozonator device, which has a configuration of two similar parallel electrodes.

\section{METHODOLOGY}

\subsection{Research Sample and Population}

The study focuses on Malaysian Standard (MS) ISO (International Organization for Standardization) 14001 certified manufacturing firms in Malaysia in order to answer the research questions and to accomplish the research objectives. This particular type of company was chosen because it tends to adopt green practices and initiatives within its systems (Zhu et al., 2008; Darnall et al., 2008). According to the Federation of Malaysian Manufacturers (FMM) and the Standards and Industrial Research Institute of Malaysia (SIRIM). in August 2014 there were 722 ISO 14001 certified manufacturing companies in Malaysia. Each company selected as a sample was represented by personnel at the management level who had been appointed to deal with and take care of the Environmental Management System (EMS) or ISO documentation in the company. Therefore, the organization is the unit of analysis applied in this study.

\subsection{Data Collection Method and Procedure}

Survey questionnaires were used for the data collection. In order to accomplish the research objectives, a total of 500 questionnaire forms were delivered by mail to the manufacturing firms' addresses. A total of 100 questionnaire were also been mailed online. Both paper and electronic format questionnaire forms were targeted at management level, as respondents for the study. Specifically, the study focuses on personnel who are in charge of or are responsible for the environmental management system or ISO documentation in the organization. Out of the 600 questionnaire forms distributed by mail and online, a total of 107 were returned, equal to a $17.8 \%$ response rate. Despite this very low rate, which was mainly due to the lack of respondent 
cooperation, budget limitations and time constraints, the sample size of the study is in line with Yamane (1967), who states that with a population size is 700, a sample size of 88 is considered as sufficient. The more data collected the better, as a higher sample size will improve statistical power (Martin \& Bateson, 2007).

\subsection{Questionnaire Design}

A questionnaire survey was developed in order to investigate the relationship between technological integration and sustainable performance among manufacturing firms in Malaysia. A number of instruments were incorporated, through which quantitative data were collected on every variable of interest. The questionnaire consisted of a variety of both previously validated instruments and measures developed specifically for the purpose of this study, designed to answer the research questions. It was designed in both electronic and paper format in order to adapt to respondent preferences and made use of a five point scale, from $1=$ low to $5=$ high. The Statistical Package for Social Science (SPSS) version 20.0 was used to analyze the data, as presented in the following section.

In this experiment, $\mathrm{CO}$ and $\mathrm{O}_{2}$ were the two gas products obtained from the plasma conversion of pure $\mathrm{CO}_{2}$. This paper mainly focuses on the effect of different processing parameters on $\mathrm{CO}_{2}$ conversion and energy efficiency and the optimization of these parameters to provide valuable information for the development of a cost-effective plasma process for $\mathrm{CO}_{2}$ conversion.

\section{RESULTS AND FINDINGS}

\subsection{Factor Analysis}

Table 1 shows the outcomes of the factor analysis for the independent variable, technological integration. The independent variables were measured in five dimensions, using 32 items that were subjected to principal component analysis (PCA) using SPSS version 20. PCA was performed to find the factors of the construct (Hair et al., 2010). In addition, the main objective of the factor analysis was to reduce a high number of variables into an interpretable and meaningful set of factors.

Table 1 Results of factor analysis for the independent variable

\begin{tabular}{cclr}
\hline Item & Component & \\
\hline tech1 & 0.777 & Eigenvalue & 5.324 \\
tech2 & 0.928 & Percentage of Variance (\%) & 74.777 \\
tech3 & 0.936 & KMO & 0.808 \\
tech4 & 0.863 & Bartlett's Test of Sphericity & 246.751 \\
tech5 & 0.904 & Significance & 0.000 \\
tech6 & 0.754 & & \\
tech7 & 0.874 & & \\
\hline
\end{tabular}

The communality value for the independent variable is greater than 0.6 , as suggested by Kim and Mueller (1994), therefore none of the items had to be deleted in order to increase factor loading. As shown in Table 1, the factor loading of the variable representing GSCI is above 0.7, so can be considered as excellent (Hair et al., 2008). The value of technology integration under the Kaiser-Meyer-Olkin measure of sampling adequacy is 0.809 ; the recommended value of 0.6 is therefore exceeded according to this result (Tabachnick \& Fidell, 2007). Barlett's test of sphericity also reached statistical significance, thereby supporting the factorability of the dimension. The PCA also reveals the availability of components with eigenvalues exceeding 1 for the independent variable, explaining the percentage of variance for technological integration $(74.777 \%)$. Thus, the items used to measure technological integration all supported. 
Table 2 shows the dependent variable, sustainable performance with three dimensions, which was measured by 16 items. Using SPSS Version 20, this variable was subjected to principal component analysis (PCA). Inspection of the factor loading for each dimension reveals the presence of a value above 0.7, which can be considered as excellent (Hair et al., 2008). Also referring to Table 2, the KMO value for sustainable economic performance (the first dimension) is 0.823 . Meanwhile, the $\mathrm{KMO}$ value for sustainable environmental performance (the second dimension) is 0.791 and for sustainable social performance it is 0.804 . The KMO value of these three dimensions exceeds 0.6, which is the recommended value (Tabachnick \& Fidell, 2007), and the factorability of the dimensions is supported, as there is statistical significance in Barlett's Test of Sphericity, as suggested by Kim and Mueller (1994). The PCA reveals the presence of sustainable economic, environmental and social performance, with eigenvalues exceeding 1, which implies that, the dimension of economic explains $82.058 \%$ of the variance. Sustainable environmental performance explains a total of $85.706 \%$ of the variance, and sustainable social performance $84.288 \%$ of the variance. Therefore, the 16 items used to represent sustainable performance were maintained.

Table 2 Results of factor analysis for the sustainable performance dimensions

\begin{tabular}{lclr}
\hline \multicolumn{1}{c}{ Item } & Component & \\
\hline economic1 & 0.940 & Eigenvalue & 4.103 \\
economic2 & 0.933 & Percentage of Variance (\%) & 82.058 \\
economic3 & 0.955 & KMO & 0.823 \\
economic4 & 0.950 & Bartlett's Test of Sphericity & 157.977 \\
economic5 & 0.733 & Significance & 0.000 \\
environmental1 & 0.909 & Eigenvalue & 5.142 \\
environmental2 & 0.962 & Percentage of Variance (\%) & 85.706 \\
environmental3 & 0.881 & KMO & 0.791 \\
environmental4 & 0.917 & Bartlett's Test of Sphericity & 246.986 \\
environmental5 & 0.943 & Significance & 0.000 \\
environmental6 & 0.940 & & \\
social1 & 0.893 & Eigenvalue & 4.214 \\
social2 & 0.958 & Percentage of Variance (\%) & 84.288 \\
social3 & 0.918 & KMO & 0.804 \\
social4 & 0.929 & Bartlett's Test of Sphericity & 168.591 \\
social5 & 0.891 & Significance & 0.000 \\
\hline
\end{tabular}

\subsection{Reliability Test}

The main purpose of a reliability test is to measure the goodness of the data, which includes the internal consistency and stability of the items (Hair et al., 2010). Cronbach's alpha of each variable is represented in Table 3.

Table 3 Cronbach's alpha of each variable

\begin{tabular}{lc}
\hline \multicolumn{1}{c}{ Variable } & Cronbach's alpha \\
\hline Technological Integration & 0.940 \\
Sustainable Performance & 0.977 \\
Sustainable Economic Performance & 0.941 \\
Sustainable Environmental Performance & 0.964 \\
Sustainable Social Performance & 0.952 \\
\hline
\end{tabular}

Table 3 indicates Cronbach's alpha for each variable in the study. From the results, sustainable performance has the highest value of 0.977 , with the three dimensions being sustainable 
economic performance 0.941 ; sustainable environmental performance 0.964 ; and sustainable social performance 0.952 , with technological integration at 0.940 . Based on the results obtained, the internal consistency among all the dependent and independent variable items is considered as very good, being above 0.9 , as suggested by Sekaran (2003).

\subsection{Normality Test}

After performing the reliability test, the data needed to undergo a screening process, known as a normality test. This is required to ensure normal distribution of data and inspection of the outliers (Hair et al., 2010). As a result, the distribution of the data in the study is normal. Besides, the assessment of normality had already proven that the data used were also normally distributed by using the Q-Q plot. Table 4 shows the normality test results.

Table 4 Normality test

\begin{tabular}{lccccc}
\hline \multicolumn{1}{c}{ Variable } & Mean & Skewness & Kurtosis & $\begin{array}{c}\text { Z-value } \\
\text { (Skewness) }\end{array}$ & $\begin{array}{c}\text { Z-value } \\
\text { (Kurtosis) }\end{array}$ \\
\hline Technological Integration & 3.11 & 0.187 & -0.896 & 0.49 & -1.08 \\
Sustainable Performance & 3.28 & -0.536 & -0.641 & -1.26 & -0.77 \\
Sustainable Economic Performance & 3.29 & -0.342 & -0.448 & -0.80 & -0.54 \\
Sustainable Environmental Performance & 3.28 & -0.501 & -0.658 & -1.17 & -0.79 \\
Sustainable Social Performance & 3.26 & -0.261 & -0.690 & -0.61 & -0.83 \\
\hline
\end{tabular}

Based on Table 4, technological integration has a mean value of 3.11, with skewness of 0.087 and kurtosis of -0.896 . The mean value for sustainable performance is 3.28 , with skewness of 0.536 and kurtosis of -0.641 , while for its dimensions the sustainable economic performance mean value is 3.29 , with skewness of -0.342 and kurtosis of -0.448 ; the sustainable environmental performance mean is 3.28 , with skewness of -0.501 and kurtosis of -0.658 ; and the sustainable social performance mean has a value of 3.26, with skewness of -0.261 and kurtosis of -0.690 . Overall, the value for skewness and kurtosis for each variable is near to zero, as suggested by Hair et al. (2010) in determining the normal distribution of data. Furthermore, the $\mathrm{z}$-value for both the skewness and kurtosis of each variable is between the range of -2 and +2 ; this is considered to be acceptable to prove normal univariate distribution (George \& Mallery, 2010).

\subsection{Analysis of Pearson's Correlation}

This analysis was performed in order to determine the strength and type of relationship that exists between the hypothesis variables. Therefore, to achieve the objective of the study, Pearson's correlation was used to evaluate the relationship between GSCI (technological integration) and sustainable performance (sustainable economic, environmental and social performance). A one-tailed test was used since the hypothesis statements stipulate that the direction of the relationships should be positive. Table 5 shows the results of the Pearson's correlation analysis.

Table 5 Correlation between Independent Variables and Sustainable Performance $(\mathrm{N}=107)$

\begin{tabular}{ccccc}
\hline \multirow{2}{*}{ Variable } & \multicolumn{4}{c}{ Pearson Correlation } \\
\cline { 2 - 5 } & SP & ECO & ENV & SOCIAL \\
\hline Technological Integration & $0.678^{* *}$ & $0.617^{* *}$ & $0.584^{* *}$ & $0.654^{* *}$ \\
\hline
\end{tabular}

${ }^{* *}$ Correlation is significant at the 0.01 level (1-tailed) 
Table 5 shows the significance between technological integration and sustainable performance and the dimensions of sustainable economic, environmental and social sustainable performance at the 0.01 level. The results support the hypotheses.

\subsection{Multiple Regression Analysis}

Multiple regression analysis was performed to identify the best predictor influencing sustainable performance among manufacturing firms in Malaysia that are ISO 14001 certified. The variables of technological integration were tested using multiple regression to achieve the objective of the study.

Table 6 Multiple regression results

\begin{tabular}{cccccc}
\hline R & R Square & Adjusted Square & R Std. Error of the Estimate & F & Sig \\
\hline 0.769 & 0.592 & 0.572 & 0.57672 & 29.283 & .000 \\
\hline \multicolumn{7}{c}{ Dependent Variable: Sustainable Performance } \\
\hline Model & Standard Coefficient Beta & T & Sig \\
\hline (Constant) & & & 2.105 & 0.038 \\
Technological Integration & & 0.367 & 3.742 & 0.000 \\
\hline
\end{tabular}

The regression results in Table 6 show that green supply chain integration with technological integration jointly explain $59.2 \%$ of the variance in predicting sustainable performance. The GSCI model proposed is significant at the 0.00 level $(F=29.283 ; p=0.000)$. Technological integration (beta $=0.367 ; \mathrm{p}=0.000$ ) is found to have statistically significant associations with sustainable performance. Therefore, technological integration is a strong predictor in influencing sustainable performance among MS ISO certified manufacturing firms in Malaysia, based on the findings of this analysis.

\section{CONCLUSION}

Technological integration has been found to have a positive relationship with the three dimensions of sustainable performance. As a result, all the hypotheses proposing a linkage between technology integration and sustainable performance (economic, environmental and social) can be supported. These results significantly prove the positive relationship between technological integration and sustainable performance. The study fills the gap in the literature on technological integration as a crucial variable of GSCI, despite being an excellent tool for integrating green supply chain partners more efficiently, leading to the enhancement of environmental performance. Based on the multiple regression analysis, the results reinforce the fact that technological integration is a necessity and a key driver in most industries towards environmental achievements. Although there are certain challenges to technological integration, such as the difficulty in obtaining the latest green manufacturing technologies, the high cost, the considerable requirement of managerial techniques, and the expertise needed, manufacturing firms in Malaysia should consider technological integration as a strong predictor of sustainable performance. However, such integration still requires involvement from suppliers, customers and internally to improve the exchange of technological knowledge. The findings of the hypothesis testing have established that the use of an integrated technological process along with the green supply chain would improve sustainable performance. Technological integration has been found to have a significant influence on sustainable performance.

\section{LIMITATIONS AND FUTURE RESEARCH}

The study employs a cross-sectional design; however, the benefits of technological integration may be realized over the long term. In addition, the results might not be generalizable in developed or other developing countries with different social, environmental and economic 
situations. Moreover, there was low response rate from companies due to issues of confidentiality, although it can be considered sufficient for analysis. Therefore, future similar studies could employ a longitudinal approach, as the benefits of technological integration and sustainable performance can be realized over the long rather than short term. Additionally, future studies could investigate the relationship between the constructs in countries with different social, environmental and economic situations. Researchers could employ a qualitative method to collect data if there are no time or cost implications. Finally, more dimensions could be introduced into the constructs considered in this study.

\section{ACKNOWLEDGEMENT}

We would like to express our gratitude to the Research and Innovation Management Centre (RIMC), Universiti Utara Malaysia (UUM) for giving us the opportunity to conduct this beneficial research through a CoE Research Grant (S/O code 13734).

\section{REFERENCES}

Abdullah, R., Hassan, M.G., Johari, N.A., 2014. Exploring the Linkage of Supply Chain Integration between Green Supply Chain Practices and Sustainable Performance: A Conceptual Link. In: $4^{\text {th }}$ International Conference on Future Environment and Energy IPCBEE, Volume 61(22), pp. 116-120

Amrina E., Yusof, S.M., 2011. Key Performance Indicators for Sustainable Manufacturing Evaluation in Automotive Companies. In: 2011 IEEE International Conference on Industrial Engineering and Engineering Management, pp. 1093-1097

Andiç, E., Yurt, Ö., Baltacioğlu, T., 2012. Green Supply Chains: Efforts and Potential Applications for the Turkish Market. Resources, Conservation and Recycling, Volume 58, pp. 50-68

Berawi, M.A., 2017a. Fostering Partnerships and Strategic Alliances in Sustainable Infrastructure Development. International Journal of Technology, Volume 8(4), pp. 568571

Berawi, M.A., 2017b. The Role of Technology in Achieving Sustainable Development Goals. International Journal of Technology, Volume 8(3), pp. 362-365

Bessire, D., Onnée, S., 2010. Assessing Corporate Social Performance: Strategies of Legitimation and Conflicting Ideologies. Critical Perspectives on Accounting, Volume 21(6), pp. 445-467

Brent, A.C., Labuschagne, C., 2004. Sustainable Life Cycle Management: Indicators to Assess the Sustainability of Engineering Projects and Technologies. In: 2004 IEEE International Engineering Management Conference

Bushar, A., Zanwar, A. Jain N., Rao, P.H., 2014. Technological Integration for Efficient and Sustainable Supply Chain in Indian Multi-brand Retail, A Real Life Application of Business Analytics. Available Online at http://analyticsindiamag.com/, Accessed on December $30^{\text {th }}, 2014$

Chen, Y., Okudan, G.E., Riley, D.R., 2010. Sustainable Performance Criteria for Construction Method Selection in Concrete Buildings. Automation in Construction, Volume 19(2), pp. 235-244

Chien, M.K., Shih, L.H., 2007. An Empirical Study of the Implementation of Green Supply Chain Management Practices in the Electrical and Electronic Industry and Their Relation to Organizational Performances. International Journal of Environmental Science and Technology, Volume 4(3), pp. 383-394 
Dangelico, R.M., Pujari, D., 2010. Mainstreaming Green Product Innovation: Why and How Companies Integrate Environmental Sustainability. Journal of Business Ethics, Volume 95(3), pp. 471-486

Darnall, N., Jolley, G.J., Handfield, R., 2008. Environmental Management Systems and Green Supply Chain Management: Complements for Sustainability? Business Strategy and the Environment, Volume 17(1), pp. 30-45

Dunphy, D., 2011. Chapter 1 Conceptualizing Sustainability: The Business Opportunity. In: Business and Sustainability: Concepts, Strategies and Changes, Book Series of Critical Studies on Corporate Responsibility, Governance and Sustainability, Eweje, G., Perry, M., (eds.), Volume 3, Emerald Group Publishing Limited

Eltayeb, T.K., Zailani, S., Ramayah, T., 2011. Green Supply Chain Initiatives among Certified Companies in Malaysia and Environmental Sustainability: Investigating the Outcomes. Resources, Conservation and Recycling, Volume 55(5), pp. 495-506.

George, D., Mallery, M., 2010. SPSS for Windows Step by Step: A Simple Guide and Reference, 17.0 update. 10a edition. Pearson, Boston

Green Jr, K.W., Zelbst, P.J., Meacham, J., Bhadauria, V.S., 2012. Green Supply Chain Management Practices: Impact on Performance. Supply Chain Management: An International Journal, Volume 17(3), pp. 290-305

Gunasekaran, A., Lai, K., Cheng, T.C.E., 2008. Responsive Supply Chain: A Competitive Strategy in A Networked Economy. Omega, Volume 36(4), pp. 549-564

Hair, J.F.J., Money, A.H., Samouel P., Page, M., 2008. Research Method for Business. John Wiley \& Sons, West Sussex, England

Hair, J.F., Black, W.C., Babin, B.J., Anderson, R.E., 2010. Multivariate Data Analysis. $7^{\text {th }}$ ed, Prentice Hall, Inc., New Jersey

Huber, N., Michael, K., McCathie, L., 2007. Barriers to RFID Adoption in the Supply Chain. In: $20071^{\text {st }}$ Annual RFID Eurasia, 5-6 September 2007, Istanbul, Turkey

International Energy Annual Report (IEA), 2007. International Bioenergy Annual Report

Junquera, B., del Brío, J.Á., Fernández, E., 2012. Clients' Involvement in Environmental Issues and Organizational Performance in Businesses: An Empirical Analysis. Journal of Cleaner Production, Volume 37, pp. 288-298

Kim, J.O., Mueller, C.W., 1994. Introduction to Factor Analysis: What It Is and How to Do It. In: Factor Analysis and Related Techniques, Lewis-Beck, M.S., (ed.), Sage Pubns, Singapore

Koufteros, X., Vonderembse, M., Jayaram, J., 2005. Internal and External Integration for Product Development: The Contingency Effects of Uncertainty, Equivocality, and Platform Strategy. Decision Sciences, Volume 36(1), pp. 97-133

Kusrini, E., Harjanto, S., Yuwono, A.H., 2015. Applications of A Green Chemistry Design, A Clean Environment, and Bioenergy to Promote the Sustainability and Added Value of Products. International Journal of Technology, Volume 6(7), pp. 1065-1068

Liu, S., Kasturiratne, D., Moizer, J., 2012. A Hub-and-spoke Model for Multi-dimensional Integration of Green Marketing and Sustainable Supply Chain Management. Industrial Marketing Management, Volume 41(4), pp. 581-588

Martin, P., Bateson, P., 2007. Measuring Behaviour: An Introductory Guide. Cambridge University Press, Cambridge

Mazzi, A., Mason, C., Mason, M., Scipioni, A., 2012. Is It Possible to Compare Environmental Performance Indicators Reported by Public Administrations? Results from An Italian survey. Ecological Indicators, Volume 23, pp. 653-659

Montabon, F., Sroufe, R., Narasimhan, R., 2007. An Examination of Corporate Reporting, Environmental Management Practices and Firm Performance. Journal of Operations Management, Volume 25(5), pp. 998-1014 
Nidumolu, R., Prahalad, C.K., Rangaswami, M.R., 2009. Why Sustainability is Now the Key Driver of Innovation. Harvard Business Review, Volume 87(9), pp. 56-64

Organisation for Economic Co-operation and Development (OECD), 2009. Input-Output Tables (IOTs), Paris

Sekaran, U., 2003. Research methods for business: A skill building approaches. $4^{\text {th }}$ ed. John Wiley \& Sons, USA

Setiawan, E.A., Asvial, M., 2016. Renewable Energy's Role in a Changing World. International Journal of Technology, Volume 7(8), pp. 1280-1282

Shi, L.X., Lin, K.X., 2003. The Integrated Strategies of the Enterprises within Green Supply Chain. Journal of Industrial Sustainable Development, Volume 12, pp. 11-18

Tabachnick B.G., Fidell, L.S., 2007. Experimental Designs using ANOVA. Duxburry Press, Belmont

Teraji, S., 2009. A Model of Corporate Social Performance: Social Satisfaction and Moral Conduct. The Journal of Socio-Economics, Volume 38(6), pp. 926-934

Vachon, S., 2003. Green Supply Chain Practices: An Examination of Their Antecedents and Performance Outcomes. PhD Dissertation, University of Western Ontario, Ontario

Wong, C.Y., Wong, C.W., Boon-Itt, S., 2015. Integrating Environmental Management into Supply Chains: A Systematic Literature Review and Theoretical Framework. International Journal of Physical Distribution \& Logistics Management, Volume 45(1/2), pp. 43-68

Wu, G., 2013. The Influence of Green Supply Chain Integration and Environmental Uncertainty on Green Innovation in Taiwan's IT industry. Supply Chain Management: An International Journal, Volume 18(5), pp. 539-552

Yamane, T., 1967. Statistics: An Introductory Analysis. $2^{\text {nd }}$ ed, Harper \& Row, New York

Zhu, Q., Sarkis, J., 2007. The Moderating Effects of Institutional Pressures on Emergent Green Supply Chain Practices and Performance. International Journal of Production Research, Volume 45(18/19), pp. 4333-4355

Zhu, Q., Sarkis, J., Cordeiro, J.J., Lai, K., 2008. Firm-level Correlates of Emergent Green Supply Chain Management Practices in the Chinese Context. Omega, Volume 36(4), pp. 577-591 